\title{
Prevalence of Glaucoma in India: A Review
}

\author{
Ronnie George, Lingam Vijaya \\ Medical Research Foundation, Sankara Nethralaya, Chennai, India
}

Glaucoma is estimated to affect 60.5 million persons worldwide by the year 2010. ${ }^{1}$ The estimated prevalence of glaucoma for India is 11.9 million. ${ }^{2}$ These estimates have been derived from population based studies conducted worldwide. The availability of population based data from India is relatively recent as compared to Western countries. We present a summary of the findings from different population based studies in the country.

These have been five populations based studies, three from the state of Tamil Nadu, one from Andhra Pradesh and one from Bengal (Table 1). ${ }^{2-6}$ Data from North India is unfortunately lacking. These studies have been carried out from 1993 to 2003. To our best knowledge at least one more population based study (from Central India) is underway. All these studies have used differing methodology and diagnostic criteria for glaucoma. To improve comparability the prevalence reported by different studies has been age standardized to the population of India (2001 census) where possible. A summary of the study design and diagnostic criteria is provided in Table 1.

\section{Diagnostic Criteria}

The diagnostic criteria for glaucoma used by the different studies have varied. All have required optic disc changes to diagnose glaucoma. Most have not used intraocular pressure for glaucoma diagnosis except when visual field or optic disc data is not available. This is in accordance with the International Society for Geographical and Epidemiological Ophthalmology (ISGEO) emphasis on structural (optic disc) or functional (visual field ) damage to diagnose glaucoma. The Chennai Glaucoma Study (CGS) and the West Bengal Glaucoma Study (WBGS) used the ISGEO guidelines for diagnosing glaucoma in population based studies. ${ }^{7}$

Ocular hypertension: The rates of OHT have been reported from the VES, ${ }^{2}$ APEDS ${ }^{8}$ and ACES. ${ }^{4}$ There are wide variations in the reported rates. The APEDS reported the lowest rate of $0.42 \%$ (95\% CI: 0.11, 1.12\%). There were 1.1\% (95\% CI: 0.84, $1.41 \%$ ) persons with OHT among those aged 40 years and older in ACES. The VES reported that 3.08\% (95\% CI: 1.98, 4.19\%) were ocular hypertensive. Pseudoexfoliation was commonly associated with ocular hypertension $4.22 \%$ of those with PXF in the $\mathrm{ACES}^{9}$ and $9.33 \%$ of those with PXF in the CGS (Rural) were ocular hypertensive. ${ }^{10}$

Primary open angle glaucoma: There are again wide variations in the prevalence of POAG between the five studies (Table 2). The VES reported the lowest rates of $0.41 \%{ }^{2}$ There are a number of reasons for this, the prime cause being that the study was limited to the age group of 30-60 years. The prevalence of POAG increased with age in all the studies discussed here. On comparing the prevalence of POAG in those is the 30-60 age group from APEDS $(1.01 \%)^{8}$ the VES reported prevalence is not dissimilar $(0.41 \%$, $95 \%$ CI: $0.08,0.81 \%)$. The other possible reason is the low rate of visual field performance in the VES. Since a visual field defect was essential for diagnosis, those who did not perform visual fields would not be classified as

Table 1: Summary of the different population based studies from India

\begin{tabular}{|c|c|c|c|c|c|c|c|}
\hline Study & Study period & Setting & Age group & $\begin{array}{l}\text { Number examined } \\
\text { (response rate \%) }\end{array}$ & $I O P$ & Optic Disc & Visual Fields \\
\hline VES & 1994 & Urban & $30-60$ & 972 (50.3) & $+/-$ & + & + \\
\hline APEDS & $1996-2000$ & Rural, Urban & All ages & $10,273(87.3)$ & - & + & $+1-$ \\
\hline ACES & 1995-97 & Rural & $40+$ & $5150(93.0)$ & - & + & $+1-$ \\
\hline CGS & 2001-03 & Rural, Urban & $40+$ & $7774(81.0)$ & $-*$ & + & $+1-$ \\
\hline WBGS & 1998-99 & Rural & $50+$ & 1324(83.1) & $-*$ & + & $+/-$ \\
\hline
\end{tabular}

*The CGS and the WBGS used the ISGEO criteria (with minor modifications) to diagnose disease. An IOP level that exceeds the $99.5^{\text {Th }}$ percentile for a normal population is used to diagnose disease only when the optic disc cannot be visualized and visual fields are not possible. 
Ronnie George, Lingam Vijaya

Table 2: Age wise prevalence of POAG in different studies

\begin{tabular}{|c|c|c|c|c|c|c|c|c|c|c|}
\hline & $\begin{array}{c}\text { APEDS } \\
(n=934)\end{array}$ & $P O A G$ & $\begin{array}{c}\text { ACES } \\
(n=5150)\end{array}$ & $P O A G$ & $\begin{array}{l}\text { CGS (Rur) } \\
(n=3924)\end{array}$ & $P O A G$ & $\begin{array}{l}\text { CGS (Urban) } \\
(n=3850)\end{array}$ & $P O A G$ & $\begin{array}{c}\text { WBGS } \\
(n=1269)\end{array}$ & $P O A G$ \\
\hline $40-49$ & 395 & 1.27 & 2066 & 0.34 & 1585 & 0.63 & 1419 & 2.26 & - & \\
\hline $50-59$ & 260 & 2.31 & 1466 & 1.57 & 985 & 1.62 & 1120 & 3.57 & 628 & 2.55 \\
\hline $60-69$ & 184 & 4.89 & 1201 & 1.83 & 892 & 2.58 & 906 & 4.08 & 409 & 2.69 \\
\hline $\begin{array}{c}70+ \\
\text { Reported }\end{array}$ & 95 & 6.32 & 417 & 2.88 & 462 & 3.25 & 405 & 6.42 & 231 & 4.76 \\
\hline $\begin{array}{l}\text { prevalence \% } \\
\text { (95\% CI) }\end{array}$ & & $\begin{array}{c}2.56 \\
(1.22,3.91)\end{array}$ & $\begin{array}{c}1.7 \\
(1.3,2.1)\end{array}$ & & $\begin{array}{c}1.62 \\
(1.42,1.82)\end{array}$ & & $\begin{array}{c}3.51 \\
(3.04,4.0)\end{array}$ & & & 2.99 \\
\hline
\end{tabular}

VES reported prevalence ( $30-60 \mathrm{yrs}): 0.41 \%$ ( 95\%CI: 0.08,0.81)

glaucoma, the high (51.5 \%) non response rates could affect case detection. With the exception of the VES the reported prevalence rates for POAG appeared to be higher in urban population (CGS (Urban) ${ }^{11}$ and APEDS ${ }^{8}$ ). While the urban populations were older than the rural population this is not the reason for the increased prevalence as the age standardized rates (to the Indian Population 2001) (Table 3) show the same trend. Urban India is known to have higher reported rates of diabetes and cardio-vascular diseases. We speculate that lifestyle changes and their related cardio-vascular influences may account in part of this increase in prevalence.

The proportion of persons with POAG who presented with a "normal" IOP(defined as two standard deviations above the population mean) was significant in all the prevalence studies. Sixty five percent of those with POAG in APEDS, ${ }^{8} 45 \%$ in ACES, ${ }^{4}$ $67 \%$ in CGS (rural) ${ }^{12}$ and $82 \%$ in CGS (urban) ${ }^{11}$ had a normal presenting intraocular pressure. This is again one of the contributory factors for the large proportion of undiagnosed disease - a single normal IOP does not rule out disease. Optic disc evaluation is mandatory in order to identify those with glaucoma.

Risk factors: Increasing age was the consistent risk factor for all studies. Males were at greater risk of POAG in the ACES. ${ }^{4}$ No gender difference was reported by any of the other studies.
Table 3: Age standardized rates for POAG, PACG, angle closure disease and PXF for the population aged above 40 years (Standardized to the population of India 2001 census)

\begin{tabular}{lllll}
\hline Study & PXF & POAG & PACG & $\begin{array}{l}\text { Angle closure } \\
\text { disease }\end{array}$ \\
\hline APEDS & 1.94 & 2.85 & 1.21 & 3.71 \\
ACES & 6.15 & 1.26 & $\mathrm{NR}$ & $\mathrm{NR}$ \\
CGS (Rural) & 3.62 & 1.58 & 0.85 & 7.75 \\
CGS (Urban) & NR & 3.46 & 0.80 & 10.43 \\
WBGS & NR & 3.06 & NR & NR \\
\hline
\end{tabular}

NR : Not reported/ age wise prevalence not reported. VES data not available. WBGS data reported only for the $50+$ age group (Age Standardized POAG prevalence: $3.06 \%$. Comparable adjusted rates for POAG in the $50+$ age group: APEDS $=4.00 \%$, ACES $=1.93 \%$, CGS(R) $=2.28 \%$, CGS $(\mathrm{U})=4.34 \%$.

Myopia was also a risk factor for POAG in the ACES. No association with refractive error was reported by any of the other studies. ${ }^{4}$

Angle closure disease: The disparities in reported prevalence of angle closure disease are perhaps most representative of the influence of the different methodology and diagnostic criteria used by these studies (Table 4). Detailed information regarding

Table 4: Age wise prevalence of angle closure disease in different studies

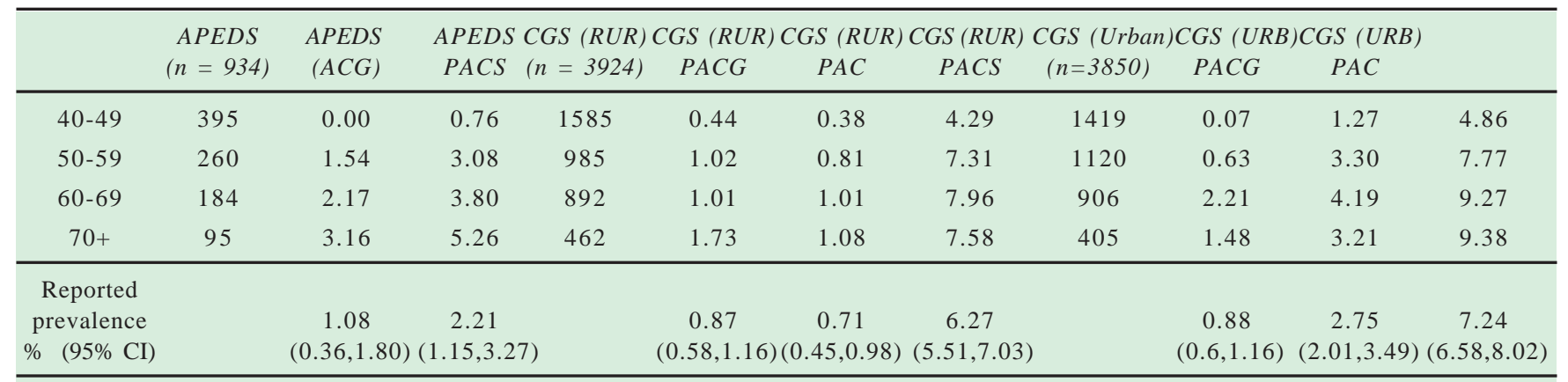

VES reported prevalence (30-60 yrs): 4.32 (95\% CI: 3.01,5.63), ACES reported prevalence (40 yrs or more): 0.5\% (95\% CI:0.3,0.7) 
the prevalence of angle closure disease (including PACG) is not available from the ACES and WBGS.

The VES was the first to report that PACG comprised a significant proportion of those with glaucoma. ${ }^{2}$ A number of persons were also reported to have occludable angles (equivalent to PACS). While the definition of "Occludability" was relatively lenient - this probably reflects clinical practice at many institutions in the country and is more stringent than the recent recommendations of the World Glaucoma Association. The VES definition of PACG encompassed those now classified as PAC in addition to those with PACG. Five persons (0.51\%) were reported to have angle closure disease with disc and field damage. These would correspond to a diagnosis of PACG; this prevalence is similar to other reported rates of PACG by studies in South India. ${ }^{4,13,14,15}$

Subsequent reports from the APEDS ${ }^{13}$ did report a lower prevalence of angle closure disease. The difference was most marked in the lower prevalence of PACS. This can partly be explained by a stricter criterion for occludability ( non visibility of the pigmented trabecular meshwork in $270^{\circ}$ or more of the filtering angle).

The prevalence of angle closure disease in the CGS ${ }^{14,15}$ is again similar to that reported by the VES. The urban area of the CGS had higher rates of PAC, PACS and PACG than the rural cohort. ${ }^{14,15}$ The VES and the CGS used similar gonioscopic criteria to diagnose a narrow angle (needing $180^{\circ}$ of the angle to be closed as defined) unlike other studies that needed threefourths of the angle to be narrow before grading as occludable. This difference in grading using 180 or $270^{\circ}$ is unlikely to result in such large discrepancies in the prevalence of angle closure disease. Glaucoma specialists are more likely to identify gonioscopic abnormality, gonioscopy in both the CGS and the VES was performed by persons with specialized glaucoma training, and could be one of the reasons contributing to the similarity in results.

In all studies the vast majority of person with PACG were asymptomatic, the disease was silent and chronic. Failure to perform gonioscopy could result in misdiagnosis as angle closure glaucoma. The CGS did report that of those with PACG who were previously diagnosed to have glaucoma $40 \%$ were misdiagnosed as POAG.

Risk factors: Increasing age was a common risk factor for PACG in all studies. Female gender (CGS) was a risk factor for PACG and PAC, ${ }^{14,15}$ more women in the APEDS had PACG but this difference was not statistically significant. ${ }^{13}$ Hyperopia was also a risk factor in the Chennai glaucoma a study (Urban), ${ }^{15}$ a trend of increased risk with hyperopia was noted both in APEDS and CGS (Rural). ${ }^{13,14}$ Among systemic conditions diabetes mellitus was reported to be a risk factor. ${ }^{15}$ Biometric data at the baseline visit was available only from the Chennai Glaucoma Study. Eyes with angle closure disease had been reported to have shorter axial length and a shallower anterior chamber and thicker lenses than normals by the CGS. ${ }^{16}$

Pseudoexfoliation is one of the risk factors for glaucoma and its prevalence in clinic based studies from India has been variously reported to be between 1.87 and $13.5 \%{ }^{9,10,17}$ Population based data on the prevalence of Pseudoexfoliation are available from three of the studies, it is reported to affect between $3 \%$ and $6 \%$ of those aged of 40 years or older. The prevalence of glaucoma among those with Pseudoexfoliation was reported to be 3.02\% in the APEDS, ${ }^{17} 7.5 \%$ in $\mathrm{ACES}^{9}$ and $13 \%$ in the rural cohort of the CGS ${ }^{10}$. The risk of Pseudoexfoliation increased with increasing age. ${ }^{9,10,17}$ No gender predilection was reported for the disease. Those predominantly involved in outdoor activities were at greater risk of PXF than those whose occupation was classified as indoor. ${ }^{17} \mathrm{~A}$ trend towards increased PXF among those from the lower socio-economic classes was also noted in the APEDS, this was however not significant. ${ }^{17}$

The wide variations in the prevalence of Pseudoexfoliation may represent inter-regional differences or may arise out of differing examination techniques.

Secondary glaucoma: The rates of secondary glaucoma have been reported by some studies. The WBGS reported a rate of $0.08 \%,{ }^{6}$ APEDS : $0.21 \%$ in those aged of 30 and above ${ }^{8,13}$ and $0.3 \%$ in the ACES. ${ }^{4}$ These reports are probably an underestimate as many of these eyes may not have had useful vision or have a disorganized anterior segment and would nor meet the diagnostic criteria of the studies.

The report from the CGS highlighting the high rates of glaucoma (11.2\% of the aphakes/pseudophakes examined) among those who had undergone cataract surgery directs attention towards a large at risk population in India. ${ }^{18}$ Those who have undergone cataract surgery are in the same age cohort at risk for glaucoma. An inadequate pre-operative assessment or poor quality of surgery may precipitate glaucoma is susceptible individuals. The higher rates of glaucoma among those with aphakia are indications of the proportion of iatrogenic glaucoma.

Blindness and glaucoma: Glaucoma is the second leading cause of blindness in the adult population in India. ${ }^{19,20}$ The proportion of those diagnosed to be bilaterally blind because of POAG in The APEDS, ACES, CGS (rural), CGS (Urban) and WBGS was $11.1 \%, 1.6 \%, 3.2 \%, 1.5 \%$ and $5.2 \%$ respectively. The corresponding figures for PACG for APEDS, CGS (rural), CGS (Urban) and WBGS were 16.6\%, 2.9\% and 5.9\%. The WBGS reported only 3 cases of PACG none of whom were blind. In those studies that reported significant rates of angle closure disease PACG caused between one and four times the proportion of blindness that POAG did.

The high rates of blindness in India can be explained, at least partially, by the large proportion of undiagnosed disease 
in the population's studies. The vast majority of disease was undiagnosed with more than $90 \%$ being diagnosed during the study examination. The ACES reported that $50 \%$ of those with glaucoma had undergone an eye examination by an ophthalmologist previously. ${ }^{4}$ Even in this group $80 \%$ of were still undetected at the time of the survey. This highlights the low case detection rates in the ophthalmic community in India.

\section{Incidence Studies in Glaucoma}

The only study from which incidence data is currently available from India is the Vellore Eye Survey, the Chennai Eye Disease Incidence Survey (CEDIS) a follow up from the Chennai Glaucoma Study cohort is currently underway.

The VES re-examined all those classified as PACS, ${ }^{21} \mathrm{PAC}^{22}$ and $\mathrm{OHT}^{23}$ five years after the initial examination in addition to examining a random subset of previously normal persons.

Eleven (22\%(95\% CI: 9.8 to 34.2)) of 50 persons with PACS progressed to develop PAC over a five years period, none progressed to PACG (seven synechial and four appositional). ${ }^{21}$ All those who progressed had bilateral PACS at baseline. Though persons with PACS had significantly shallower anterior chamber depth than normal no biometric risk factors for progression could be identified. One previously normal person progressed to PAC with time, the relative risk for progression among those with PACS to PAC was 24.2 (95\%CI: 3.2 to 182.4). Eight (28.5\%, 95\% CI: 12-45\%) of 28 persons diagnosed to have PAC at baseline progressed to PACG over similar time frame. ${ }^{22}$ Of these nine had undergone YAG PI, of whom one (11.1\%) progressed. Seven (36.8\%) of the 19 who refused YAG PI at the baseline progressed. None were blind due to glaucoma.

In both groups no patients suffered from an acute angle closure attack during the five years period.

Twenty five of the twenty nine ocular hypertensives diagnosed at baseline were re-examined. ${ }^{23}$ After correction for CCT they were reclassified as ocular hypertensive if the corrected IOP was above $21 \mathrm{~mm} \mathrm{Hg}$. Among untreated ocular hypertensives $17.4 \%$ (95\% CI: 1.95 to $32.75 \%$ ) progressed to develop POAG (optic disc and visual field changes) over a five years period. One of the normals controls had progressed to develop POAG. The relative risk of POAG among those with untreated OHT was 19.1(95\% CI: 2.2. 163.5).Those who progressed had wider diurnal fluctuations in IOP.

The numbers in each cohort are small with consequently wide confidence intervals. However, this is the only incidence study from India and gives us an estimate of the risk of disease among those with risk factors for glaucoma.

The population based studies that report glaucoma prevalence provide important information. The Indian population has substantial risk for POAG with the additional risk of PACG and large burden of angle closure disease. This assumes greater importance as the risk of all forms of glaucoma

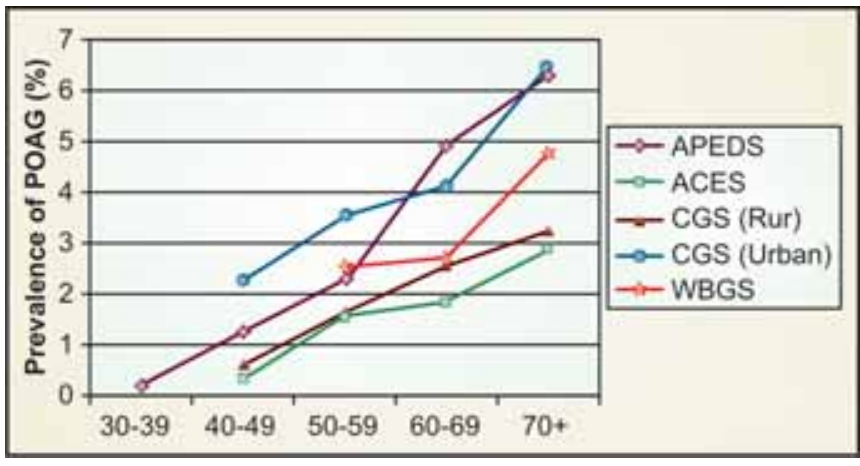

Fig. 1: Prevalence of POAG and age

increases substantially with age. The majority of the Indian population is less than 30 years of age. With increasing life expectancy the number of those at risk of glaucoma will grow exponentially over time. Improving our case detection rates is of utmost importance if we are to make an impact on the burden of disease in the country. The vast majority of glaucoma in India is undiagnosed; there is an urgent need to adopt comprehensive eye examinations, which include IOP measurement, gonioscopy and optic disc evaluation, as a routine.

\section{REFERENCES}

1. Quigley HA, Broman AT. The number of people with glaucoma worldwide in 2010 and 2020. Br J Ophthalmol 2006;90(3):2627.

2. Jacob A, Thomas R, Koshi SP, Braganza A, Muliyil J. Prevalence of primary glaucoma in an urban south Indian population. Indian J Ophthalmol 1998;46(2):81-6.

3. Arvind H, Paul PG, Raju P, Baskaran M, George R, Balu S, et al. Methods and design of the Chennai Glaucoma Study. Ophthalmic Epidemiol 2003;10(5):337-48.

4. Ramakrishnan R, Nirmalan PK, Krishnadas R, Thulasiraj RD, Tielsch JM, Katz J, et al. Glaucoma in a rural population of southern India: the Aravind comprehensive eye survey. Ophthalmology 2003;110(8):1484-90.

5. Dandona R, Dandona L, Naduvilath TJ, Nanda A, McCarty CA. Design of a population-based study of visual impairment in India: The Andhra Pradesh Eye Disease Study. Indian J Ophthalmol 1997;45(4):251-7. Review.

6. Raychaudhuri A, Lahiri SK, Bandyopadhyay M, Foster PJ, Reeves BC, Johnson GJ. A population based survey of the prevalence and types of glaucoma in rural West Bengal: the West Bengal Glaucoma Study. Br J Ophthalmol 2005;89(12): 1559-64.

7. Foster PJ, Buhrmann R, Quigley HA, Johnson GJ. The definition and classification of glaucoma in prevalence surveys. Br J Ophthalmol 2002;86(2):238-42. Review.

8. Dandona L, Dandona R, Srinivas M, Mandal P, John RK, McCarty CA, et al.Open-angle glaucoma in an urban population in southern India: the Andhra Pradesh eye disease study. Ophthalmology 2000;107(9):1702-9. 
9. Krishnadas R, Nirmalan PK, Ramakrishnan R, Thulasiraj RD, Katz J, Tielsch JM, et al. Pseudoexfoliation in a rural population of southern India: the Aravind Comprehensive Eye Survey. Am J Ophthalmol 2003;135(6):830-7.

10. Arvind H, Raju P, Paul PG, Baskaran M, Ramesh SV, George $\mathrm{RJ}$, et al. Pseudoexfoliation in South India. Br J Ophthalmol 2003;87(11):1321-3.

11. Vijaya L, George R, Baskaran M, Arvind H, Raju P, Ramesh SV, et al. Prevalence of Primary Open-angle Glaucoma in an Urban South Indian Population and Comparison with a Rural Population the Chennai Glaucoma Study. Ophthalmology 2007; [Epub ahead of print].

12. Vijaya L, George R, Paul PG, Baskaran M, Arvind H, Raju P, et al. Prevalence of open-angle glaucoma in a rural south Indian population. Invest Ophthalmol Vis Sci 2005;46(12):4461-7.

13. Dandona L, Dandona R, Mandal P, Srinivas M, John RK, McCarty CA, et al. Angle-closure glaucoma in an urban population in southern India. The Andhra Pradesh eye disease study. Ophthalmology 2000;107(9):1710-6.

14. Vijaya L, George R, Arvind H, Baskaran M, Paul PG, Ramesh $\mathrm{SV}$, et al. Prevalence of angle-closure disease in a rural southern Indian population. Arch Ophthalmol 2006;124(3):403-9.

15. Vijaya L, George R, Arvind H, Baskaran M, Ve Ramesh S, Raju $\mathrm{P}$, et al. Prevalence of Primary Angle-Closure Disease in an Urban South Indian Population and Comparison with a Rural Population the Chennai Glaucoma Study. Ophthalmology 2007; [Epub ahead of print].

16. George R, Paul PG, Baskaran M, Ramesh SV, Raju P, Arvind H, et al. Ocular biometry in occludable angles and angle closure glaucoma: a population based survey. $\mathrm{Br} \mathrm{J}$ Ophthalmol 2003;87(4):399-402.

17. Thomas R, Nirmalan PK, Krishnaiah S. Pseudoexfoliation in southern India: the Andhra Pradesh Eye Disease Study. Invest Ophthalmol Vis Sci 2005;46(4):1170-6.

18. Arvind H, George R, Raju P, Ramesh SV, Baskaran M, Paul PG, et al. Glaucoma in aphakia and pseudophakia in the Chennai Glaucoma Study. Br J Ophthalmol 2005;89(6):699-703.
19. Vijaya L, George R, Arvind H, Baskaran M, Raju P, Ramesh SV, et al. Prevalence and causes of blindness in the rural population of the Chennai Glaucoma Study. $\mathrm{Br} \mathrm{J}$ Ophthalmol 2006;90(4):407-10.

20. Thulasiraj RD, Nirmalan PK, Ramakrishnan R, Krishnadas R, Manimekalai TK, Baburajan NP, et al. Blindness and vision impairment in a rural south Indian population: the Aravind Comprehensive Eye Survey. Ophthalmology 2003;110(8):14918.

21. Thomas R, George R, Parikh R, Muliyil J, Jacob A. Five year risk of progression of primary angle closure suspects to primary angle closure: a population based study. Br J Ophthalmol 2003;87(4):450-4.

22. Thomas R, Parikh R, Muliyil J, Kumar RS. Five-year risk of progression of primary angle closure to primary angle closure glaucoma: a opulation-based study. Acta Ophthalmol Scand 2003;81(5):480-5.

23. Thomas R, Parikh R, George R, Kumar RS, Muliyil J. Five-year risk of progression of ocular hypertension to primary open angle glaucoma. A population-based study. Indian J Ophthalmol 2003;51(4):329-33.

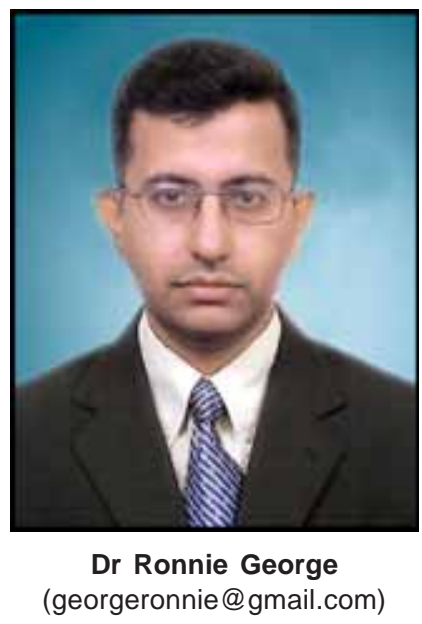

